\title{
The Effects of Oil-gas Lubrication Air Pressure on the Bearing Temperature of Motorized Spindle
}

\author{
L. X. ZHANG; T. LIU *; C. Q. LI \\ Shenyang Jianzhu University, Shenyang 110168, China \\ *Corresponding author: 1240059679@qq.com
}

Keywords: Oil-gas Lubrication, Coupled Heat Transfer, Temperature Field, Cooling.

\begin{abstract}
In order to analyze the 170SD30-SY motorized spindle bearing cooling effect of the oil-gas lubrication system, a fluid - solid coupling heat transfer model established in finite element software. It is realized by way of numerical simulations on the ground of theoretical analysis. By changing the compressed air pressure, the characters of bearing temperature was studied. Simulation results show that control the inlet air pressure in a reasonable range can make the temperature rise of the bearing control in a reasonable scope. Experiments were conducted according to the results of the simulation analysis and the experimental temperature is consistent with simulation results. Finally, a theoretical basis is offered for the parameter optimization of motorized spindle Oil-gas lubrication system which can meet the requirements of high-speed spindle bearing cooling technology.
\end{abstract}

\section{Introduction}

With the application of motorized spindle technology has been used in NC machine tool, high speed and ultra high speed machining has become the main trend. However, the bearing will produce a lot of heat when the machine tool in a high speed processing. It would be a disaster for bearing structure if the heat can't be dissipated in time ${ }^{[1]}$. Therefore, it is particularly important to control spindle bearing temperature rise. Oil-gas lubrication technology is one of the key technologies of the motorized spindle technology, which can carry away a large amount of heat when the bearing in a high-speed ${ }^{\text {[2] }}$.

Oil-gas lubrication technology, as one of the most important technologies, has been applied in motorized spindle. The company of German REBS in a world leading position, on the Oil-gas lubrication technology ${ }^{[3]}$. Some scholars have published some of the related literature on the oil-gas lubrication technology. However, for the technical privacy protection, these literature are mostly about summarize and using feedback ${ }^{[4]}$. S.H.Y made the oil-gas lubrication technology applied in ultra-high speed grinding spindle and obtained a good processing performance. Some scholars of Japan's NSK Research Center have made a deep research on the thermal mathematical model of high-speed ceramic ball bearings and verified the results by the experiment ${ }^{[5]}$. Junguo Zhang analyzed the internal temperature field of rolling bearings and found the relationship between the Lubricating oil supply quantity and the bearing temperature field ${ }^{[6]}$. Liming Xie analyzed the oil-gas two-phase flow formation process during the oil-gas lubrication system working and pointed out that only the Reynolds Number of compressed air with in 2123 to 9152 can form a suitable membrane ${ }^{\text {[7] }}$.

However, the compressed air played main role in the temperature rise of bearing when the lubricating oil supply can meet the requirement. There is little research about the coupled heat transfer analysis of the compressed air flows through the bearing ${ }^{[8]}$. Experience show it has the best cooling effect when the inlet pressure of motorized spindle oil-gas lubrication system was keep up within the range of $0.4 \mathrm{MPa}{ }^{[9]}$. It can make the temperature of the bearing controlled in the requirement scope by adjusting the pressure of the compressed air when the heat generation rate of bearing remained constant. This paper found the relationship between the bearing temperature field and the oil-gas lubrication compressed air pressure based on the method of numerical calculation.

\section{The Characteristics of 170SD30-SY Motorized Spindle Oil-gas Lubrication System}

Oil-gas lubrication of the motorized spindle that means the lubricating oil is blown into the bearing 
by the compressed air. In this way, accurate lubrication oil supply of being could be realized easily, and a part of the heat which produced by the bearing of running with high speed is carried away by compressed air. It achieved the double functions of lubrication and cooling finally ${ }^{[10]}$. Compared with the traditional grease lubrication, trace lubrication oil can be quantitatively supply to the bearing, so it can control the minimum necessary amount of oil and reduce the pollution to the working environment. Meanwhile, it has a good sealing effect for the high pressure within the internal of motorized spindle ${ }^{[11]}$. The oil-gas lubrication system work shows in the Figure1.

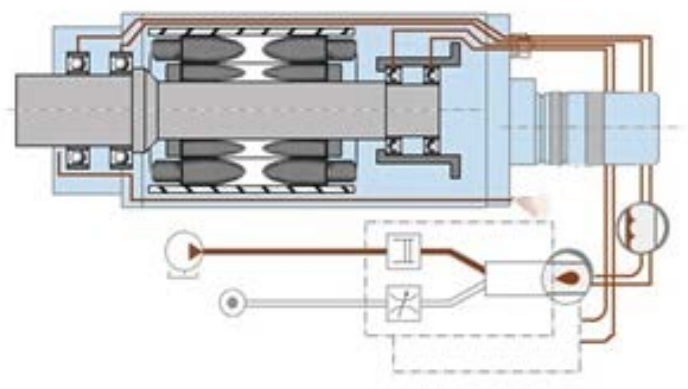

Figure 1 The work principle of oil-gas lubrication system

The purpose of this study is to find out the best air pressure of oil-gas lubrication system based on the analysis of the compressed air pressure influences on the temperature rise of the bearing ,so that can be provide a theoretical basis for optimal the parameters of the oil-gas lubrication system. It is important to analyze the oil-gas lubrication system parameters effect on the bearing temperature rise.

\section{The Finite Element Analysis Three Dimensional Modeling about Oil-gas lubrication System of} Motorized Spindle 170SD30-SY

\section{The Finite Element Model}

Based on the actual size of 7009C bearing, the model was built by the finite element software. The grid and basin shows in Figure2.

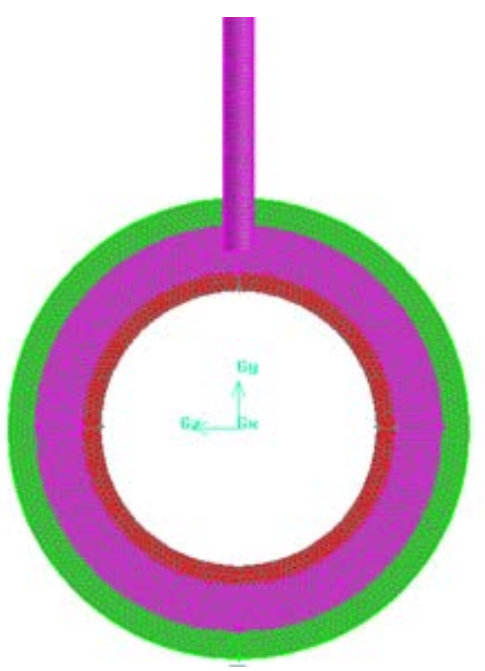

Figure 2 7009C bearing model

The control equation

The mass continuous equation

$$
\frac{\partial \rho}{\partial \mathrm{t}}+\Delta(\rho \bar{U})=0
$$

$\mathrm{N}-\mathrm{S}$ differential equation of motion 


$$
\frac{\mathrm{d}(\rho \bar{U})}{d \mathrm{t}}=\rho \overline{\mathrm{F}}-\nabla P+\mu \Delta \bar{U}
$$

The energy conservation equation

$$
\frac{\mathrm{d}\left(\rho_{C p}^{T)}\right.}{d \mathrm{t}}=\Phi+\lambda \nabla T+\rho_{q}
$$

In the formula, $\bar{U}$ is the velocity vector, $\rho$ is the fluid density, $\mathrm{P}$ is fluid pressure, $\mu$ is fluid dynamic viscosity, $C p$ is the Specific heat at constant pressure. $\lambda$ is thermal conductivity, $\bar{F}$ is the mass force on the fluid, Q is the heat absorbed by the fluid, T is the temperature of the fluid, $\Phi$ is dissipation function of energy.

\section{Setting of the boundary conditions in the finite element software}

The Dynamic Model using the standard model $\mathrm{k} \sim \mathcal{E}$, the materials using the bearing steel, the cooling air using the compressed air. The inlet uses the pressure boundary conditions and the same as the outlet. The wall of the air and the bearing set as the coupling surface. The bearing is used as the heat source. The other boundary conditions boundary is the internal boundary condition. The motorized spindle (10000r/min) operation parameters as show in table 1.

Table 1 Physical property of bearing

\begin{tabular}{cccccc}
\hline T & Cp & $\begin{array}{c}\text { Thermal } \\
\text { conductivity } \\
(\mathrm{W} / \mathrm{m} \cdot \mathrm{K})\end{array}$ & $\begin{array}{c}\text { Heat } \\
\text { generation rate } \\
\left(\mathrm{W} / \mathrm{m}^{3}\right)\end{array}$ & Density \\
$\left({ }^{\circ} \mathrm{C}\right)$ & $(\mathrm{J} / \mathrm{kg} \cdot \mathrm{K})$ & $\left.\mathrm{Kg} / \mathrm{m}^{3}\right)$ \\
\hline Bearing & 26 & 502.8 & 36.4 & 5830000 & 7850 \\
\hline
\end{tabular}

\section{Finite Element Analysis of the Simulation Results}

The analysis of the relationship between the highest temperature of the bearing and the compressed air pressure

The bearing temperature simulation analysis results were recorded with the different pressure of compressed air and shows in Figure 3.

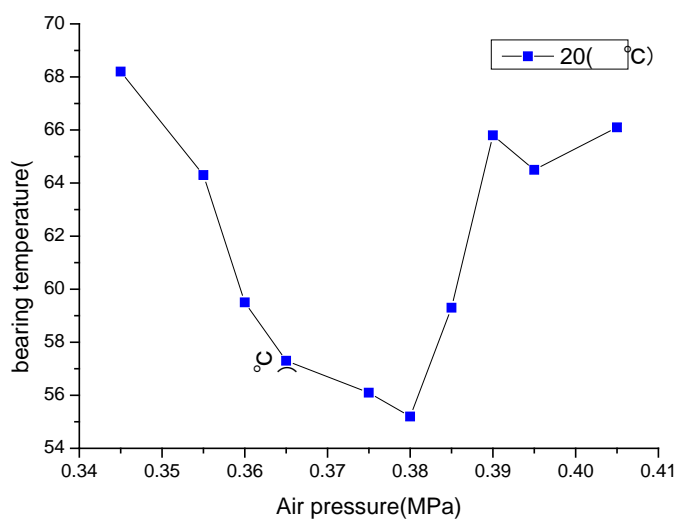

Figure 3 Relationship between the highest temperature of the bearing and the pressure of the compressed air

Figure 3 simulation results show that there exist a special pressure make the temperature of the bearing significant changed. When the pressure of compressed air in the $0.360 \mathrm{MPa} 0.382 \mathrm{MPa}$, the highest temperature of the bearing is relatively low.

When the air pressure is lower than $0.360 \mathrm{MPa}$,the heat dissipation ability deficiency which lead to the bearing temperature rised for the thermal cumulation. When the pressure is higher than $0.382 \mathrm{MPa}$, the friction increased between the air and the bearing and the energy released by the compressed air increased which lead to the bearing temperature rised. Therefore the motorized spindle 170SD30-SY 
oil-gas lubrication system should choose the suitable pressure.

\section{Bearing temperature field distribution}

Set the inlet temperature of $20{ }^{\circ} \mathrm{C}$, the inlet pressure is $0.365 \mathrm{MPa}$, the bearing temperature field distribution in Figure 4.

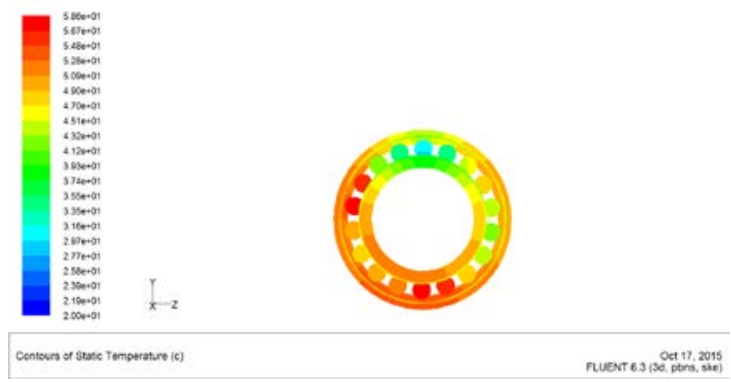

Figure 4 The bearing temperature field distribution

Fig. 4 shows the highest temperature appeared in the bearing ball bearing, outer ring and inner ring. The temperature of the air basin significantly increased for the heat exchanged and that indicated the compressed air play a cooling efficacy on the bearings.

\section{Experimental Verification}

In order to verify simulation results. The Thermocouple and multiplex temperature measurement instrument were used to test the temperature of the bearing outer ring of the motorized spindle 170SD30-SY. Figure 5 shows the thermocouple fixed on the bearing outerring.

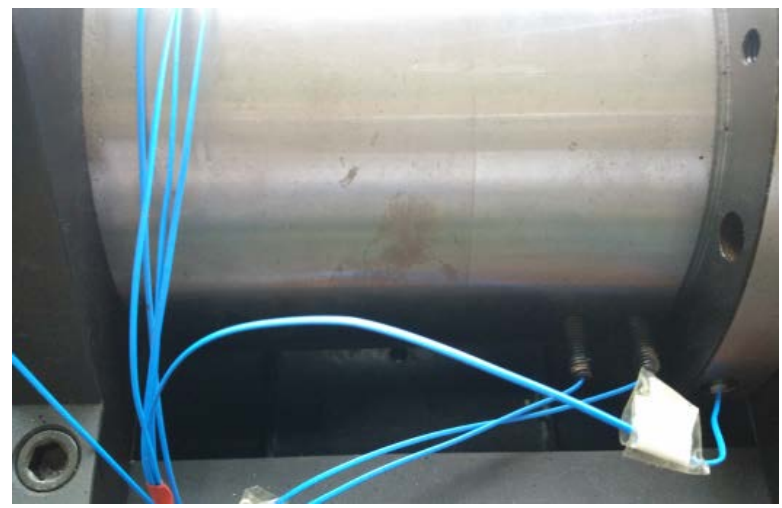

Figure 5 Thermocouple fixed on the bearing outer ring

Set the air inlet temperature of $20^{\circ} \mathrm{C}$, the relationship between the air pressure and the temperature of the bearing was shown in Figure 6.

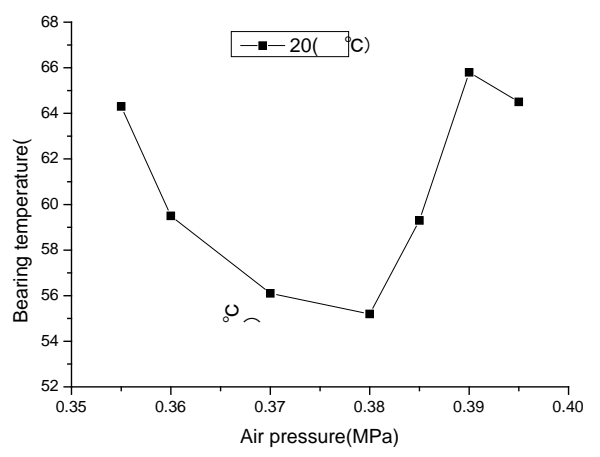

Figure 6 The relationship between air pressure and the temperature of the bearing 
Figure 6 shows that when the compressed air pressure reach in $0.36 \mathrm{MPa}$ to $0.38 \mathrm{Mpa}$, the lowest bearing temperature is obtained and the relative error is less than five percent, so the simulation results and theoretical analysis results are believable.

\section{Conclusions}

The results are consistent with our expected and are in good agreement with the calculated value.

For the oil-gas lubrication system of the motorized spindle 170SD30-SY, it has a best cooling effect on the bearing when the pressure of compressed air in the range of $0.360 \mathrm{MPa}$ to $0.382 \mathrm{MPa}$. In practical application, we should choose the pressure values.

\section{Acknowledgements}

This work is supported by the natural science foundation of china under the item (grant no. 51375317).

\section{Reference}

[1] J. Q. Jia: 'the application of oil-gas lubrication technology in the machining center spindle lubrication', Manufacturing\& materials, 2013, 5, 42-45.

[2] Z. Zhou, D. X. Xue, B. Tang and H. Meng: 'The flow and fluid-solid coupled heat transfer analysis of a medium speed diesel engine cooling system', Performance and Emissions, 2013, 35, 17-22.

[3] K. J. Hu: 'Design, application and development of oil-air lubrication system', Metallurgical equipment, 2001, 128, 36-39.

[4] E. Abele, Y. Altintas and C. Brecher: 'Machine tool spindle units', CIRP Annals-Manufacturing Technology, 2010, 59, 780-805.

[5] S. H. Yeo, K.Ramesh and Z. W. Zhong: 'Ultra-high-speed Grinding Spindle Characteristics upon Using Oil/air Mist lubrication', International Journal of Machine Tools \& Manufacture, 2002, 42, 815-823.

[6] J. G. Zhang, B. B. Gong and J. W. Wang, 'Study on the optimum oil feeding for the Rolling Bearing Lubricated with Oil-air’, Lubrication \& Sealing, 2006,182 ,168-171.

[7] L. M. Xie, X. S. Zhu and Y. Wang: 'Study on the optimum oil feeding for the Rolling Bearing Lubricated with Oil-air', the value analysis of oil-gas currents flowing process in pipeline, 2011, 72-74.

[8] S. T. Yan, Q. P. Xu and S. K. Zhang: 'Cooling system design for high speed motorized spindle', several integration technology, 2011, 8, 44-47.

[9] L. X. Zhang and Y. H. Wu: 'technology of high-speed motorized spindle of digit control machine tool, 2013, 1, 22-26.

[10]L. M. Xie, X. S. Zhu and W. Jiang: 'Oil gas two-phase forming process value simulation in oil-gas lubrication system’, Design and research, 2011, 3, 39-41.

[11]S. Y. Jiang, Z. K. Wang: 'experimental research on oil-air two phase lubrication of high speed motorized spindle rolling bearing', 2005, 11-30. 